\title{
Investigating Students Attitude Towards the Learning of Geography in Senior High Schools. A Survey of the Cape Coast Metropolis
}

\author{
Kwame Ntiamoah Ntim \\ Department of Business and Social Sciences Education, \\ University of Cape Coast, Ghana, West Africa \\ Elvis Gyamfi \\ University of Cape Coast, Ghana, West Africa \\ Marian Domfe Pomaa \\ University of Cape Coast, Ghana, West Africa \\ Alexander Owusu Afari \\ University of Cape Coast, Ghana, West Africa
}

\begin{abstract}
This study investigates the attitude of Senior High School students towards the teaching and learning of geography in the Cape Coast Metropolis. To achieve this, a quantitative approach using descriptive survey design was employed. A sample of 120 students studying geography were selected from four (4) Senior High Schools in the Cape Coast Metropolis. The study employed purposive and simple random sampling procedure to select respondents from the schools for the study. Questionnaire (close-ended) were used, and data were coded and analysed using the Statistical Package for Social Sciences (SPSS) version 22.0 to produce inferential (means and standard deviation). The study revealed that students perceive geography as difficult to learn and understand because the geography subject involves a lot of drawings and terminologies, etcetera. It was again, unraveled that students have positive attitude towards the teaching and learning of geography. The findings of the study revealed that reading materials such as textbooks, handouts etc. are used by the geography teachers in teaching. It was therefore, recommended that teachers in the various schools should motivate their students to take geography lessons seriously and study it well, as it could be of relevance to them in the near future. Government and other stakeholders should provide schools with modern teaching and learning resources so as to help teachers to explain very well Geography concepts to the understanding of their students.
\end{abstract}

Keywords: Geography, Students, Cape Coast, Attitude, Teaching, Learning

DOI: $10.7176 / \mathrm{JEP} / 11-34-01$

Publication date: December $31^{\text {st }} 2020$

\subsection{Introduction}

The student is one of the elements that are indispensable to education. Every student, in the process of education, is an individual; hence must be treated as such. Individuals with different biological structures and who come from diverse environments naturally have different points of view about events and consequently, comment on them differently. These differences result from various factors such as their past experiences, their interests and abilities, the way they learn etc. (Terry, 2006).

One of the major characteristics of modern education is that it is student-centered. In this system, students are placed in the center of education so that they become the principal focus of attention. John Dewey, who had an important part in the adoption of this method, developed the principle of "child-centered education" (Jones, 2007). As is clear from the explanations, students' abilities, expectations from education, past experiences among others are some of the most effective elements in education. These features are quite effective on the kind of attitude that a student takes to a particular lesson.

However, a student's attitude towards a lesson is not only connected with his or her personality traits. Teachers' qualifications, such as their knowledge of the field and methodology, are also important in this regard. Before one can establish students' attitudes towards Geography in second cycle educational institutions, it is necessary that answers are sought to this question: "what does attitude mean as a concept and how can it be measured?"

Attitude, generally, means somebody's tendency to react to any event or object in his or her environment. In other words, attitude can be defined as an individual's possible behaviours in a situation, occasion or towards any phenomena (Kartz, 1960).

From this point of view, it is quite natural that science of behavior deals with "attitude" as one of the key 
concepts. Investigations and inquiries about attitudes are not confined only to the science of behaviour such as psychology or social psychology. In many other fields within the frame of social sciences such as Politics, Economics, History, Geography among others, examination of attitudes is of great essence. As attitudes have no physical dimension, in other words, since they are abstract concepts, they are rather difficult to measure; that is to say, they cannot be measured directly. When people are asked about their opinion on any object or their attitude towards any topic, they usually fail to respond to it accurately and make some superficial and inaccurate statements instead (Moore, 1989). Before establishing students' attitude towards the learning of Geography in secondary schools, we need to know what Geography is and the history behind Geography in Ghana and the world over.

Geography as an academic discipline is mainly concerned with the development of knowledge about the earth as home for mankind, focusing mainly on the physical environment and human society as well as the spatial organisation of that society. The term Geography was derived from a Greek word "geo" meaning earth and "graphein" meaning to write or describe. The subject focuses mainly on the study of the surface of the earth and of the natural and physical forces which exert their influence in, on or around it.

Sir Mackinder (1887) defines geography as the study of man and his environment, with the environment being regions which show particular conditions that distinguish them from others. His point of view, with regard to Geography, was from the perspective of man being an agent of change in shaping characters of a place. As a field of study, the subject embodies two major disciplines which are: Human and Physical Geography (Rubenstein, 2003)

In the history of Ghana, Geography was added to the school curriculum during the educational reform in 1987. Much emphasis was placed on the study of Geography as early as primary two and progressed to middle school where it was made a core subject for all students. The subject was compulsory for those who entered the traditional secondary school form one through to form three where students were made to choose subjects of their own.

Many sixth and fifth formers even showed much interest in pursuing the subject. Geography obtained its identity in the Senior Secondary School Program in 1991 and re-emerged as a discipline on its own. It was, however, not a compulsory subject but an elective one. Geography at Senior High Schools level have been divided into three main categories: Physical Geography, Human Geography and Practical Geography. These three categories of learning Geography are also addressed in the objectives declared by the Ghana Education Service (Ghana Education Service, 2010). Each of these categories provide the basis of curriculum development for Senior High Schools.

The rationale behind the teaching of Geography is to, first of all, improve the communication skills of students, especially in areas of describing and evaluating environmental concerns. It also, provides students with knowledge and understanding of their communities, nation and the world. Finally, another rationale for teaching Geography is to equip students with significant skills to enable them to contribute towards improving and sustaining the environment. (Ghana Education Service, 2010).

The years of on-going changes in curriculum design, teaching methodology and administration may have helped to improve students' perception or attitude towards the learning of Geography (Fletcher, 2005). However, most students still perceive Geography as dull, boring, and irrelevant to their lives. If the Geography curriculum continues to have support from school administrators, geographers, and the general public, it is possible to have positive student attitudes towards the subject. This is important because it is quite possible that negative attitudes towards Geography could ultimately result in a sharp decline in the allocation of resources for this subject area.

As participants or student-teachers in the off-campus teaching practice and through personal discussions with other students, what we gather is that Geography is too lengthy and boring. Some opined that there are inadequate teaching and learning resources on the subject while others complain that they were forced to offer Geography. These made them show little or no interest in the subject.

From the above description of Geography education in both Ghana and the world at large, one could attest to the fact that a study of students' attitude towards the learning of Geography will be a great relevance to geographers. It is against this background that this study sought to investigate students' attitude towards the learning of Geography in Senior High Schools

\subsection{Statement of the Problem}

Geography, as one of the elective subjects in the curriculum of Senior High Schools, has become particularly important, hence, the need for students to develop a desire for and a positive attitude towards it. This, notwithstanding, the efforts of authorities to make Geography more popular among students have received a mixed reaction from students. Most of these reactions stem largely from attitudinal differences.

Apart from this, there is a perception that Geography is a male subject and for that matter, boys have a greater chance at getting the opportunity to study it to the highest level. This general notion has discouraged female students in the Senior High Schools from studying the subject.

Also, the approaches used by teachers in teaching the subject seem to be more of a lecture method because 
teachers rush to finish the syllabus in no time. Inadequate teaching and learning resources have also contributed to students' developing negative attitudes towards the study of Geography.

The irony of the problem is that, almost every other subject is becoming increasingly Geography oriented, but the problem is whether students are forming the desired attitude towards Geography. The study is therefore designed to investigate the attitude of students towards Geography in Senior High Schools in the Cape Coast metropolis.

\subsection{Purpose of the Study}

The purpose of the study is to investigate the attitude of Senior High School students towards the teaching and learning of Geography in the Cape Coast metropolis. Specifically, the study seeks to:

1. Ascertain how the Senior High School students perceive the teaching and learning of Geography.

2. Find out the attitudes of Senior High School students toward the teaching and learning of Geography.

3. Inquire about the teaching and learning resources available for the teaching and learning of Geography in the Senior High Schools.

\subsection{Research Questions}

The following research questions were formulated to guide the study:

1. How do students in Senior High School students perceive the teaching and learning of Geography?

2. What are the attitudes of Senior High School students toward the teaching and learning of Geography?

3. What teaching and learning resources are available for the teaching and learning of Geography in the Senior High Schools?

\subsection{Significance of the Study}

The findings of the study will contribute effectively in imparting knowledge in the area of teaching and learning of Geography in Senior High Schools in the Cape Coast Metropolis. This is because it will help Geography teachers in effectively and appropriately imparting knowledge to their students since the teachers would get to know and understand the perceptions of their students about the subject.

The study will also serve as a basic reference material for both teachers and educational stakeholders and other related institutions in that it would equip them to be able to solve challenges, they may encounter in dealing with issues related to the attitudes of students towards learning Geography.

\subsection{Methodology}

In this study, the design used was descriptive research design. Descriptive design made room for the concepts and issues to be well assessed by the researcher. The study made use of quantitative method. The target population of the study consisted of all students in senior high schools in Cape Coast metropolis. The accessible population were students and teachers in only four selected senior high schools in Cape Coast Metropolis. The selected schools included; Mfantsipim senior high, Adisadel College, Holy Child senior high and University Practice senior high school. We selected Cape Coast Metropolis because of the proximity of the school to one another. Second- and third-year General Arts students were used because they study courses which are related to Geography and having gone through Geography education for almost two to three years stand a better position to provide the necessary information for the data.

In selecting the schools, the researchers used the non-probability sampling method; in this respect, the targeted or purposive sampling technique was used to select the schools to be considered for the data collection. Mfantsipim Senior High School, Holy Child Senior High School, University Practice Senior High School and Adisadel College.

The simple random technique was adopted in the selection of students to respond to the items in the questionnaire. The choice of the simple random sampling was appropriate because it gives every student the chance of being selected for the research. Thirty (30) students were therefore selected in each school totaling one hundred and twenty (120) respondents for the four (4) schools selected. Questionnaire was the main instrument used for this research. The questionnaire was divided into sections according to the various research questions. The researchers together with the geography teachers gave out the questionnaires for the students to answer which was collected after 30 minutes. Data analysis was done with the use of Statistical Package for Service Solutions (SPSS version 23.0). The data was organized into various themes and categories (four sections) based on the research questions and the purpose of the study. The questionnaire was coded and tabulated for analysis. The data was further coded according to the items and transferred unto a spreadsheet which is a computer software known as Statistical Package for Service Solution (SPSS). Tables comprising of frequencies and percentages and means, and standard deviations were used in the data analyses. 


\subsection{Results and Discussions}

7.1 Research Question One: How do students in Senior High Schools perceive the teaching and learning of Geography?

To provide answer to this research question, the respondents were made to answer a four-point Likert-scale questionnaire constructed on a four-point Likert scale ranging from "Strongly Disagree (1), Disagree (2) Agree (3) and Strongly Agree (4)". The responses were then categorized into two main divisions: "Agree"' and "Disagree". The analysis of their responses is presented in Table 1.

Table 1: Distribution of Respondents by their perceptions of Geography

\begin{tabular}{lcccc}
\hline \multicolumn{1}{c}{ Statement } & \multicolumn{2}{c}{ Agree } & \multicolumn{2}{c}{ Disagree } \\
\cline { 2 - 5 } & Freq. & Freq. & \% \\
\hline 1. Geography is the easiest subject to study. & 15 & 12.5 & 115 & 87.5 \\
2. Geography is very difficult to study. & 72 & 60.0 & 48 & 40.0 \\
3. Geographers are well paid and respected & 50 & 41.7 & 70 & 58.3 \\
4.Geography students pass well than others & 41 & 34.2 & 79 & 65.8 \\
5.Geography helps me to understand the problems in the world like & 90 & 75.0 & 10 & 25.0 \\
earthquakes, volcanoes, etc. & & & & \\
6. Knowledge from Geography helps us to extend support to other nations. & 83 & 69.2 & 37 & 30.8 \\
$\begin{array}{l}\text { 7. Knowledge from Geography helps people to improve natural living } \\
\text { conditions }\end{array}$ & 82 & 68.3 & 38 & 31.7 \\
8. Geography helps me to know what is happening in other parts of the world. & 68 & 56.7 & 52 & 43.3 \\
9. Geography helps me to know how to read maps & 93 & 77.5 & 27 & 22.5 \\
10. Knowledge from Geography will help me to fit in any part of the world. & 61 & 50.8 & 59 & 49.2 \\
\hline
\end{tabular}

The data on Table 3 clearly shows the perceptions of the respondents toward the teaching and learning of Geography.

Considering the content of the Senior High School Geography subject, most $72(60.0 \%)$ of the respondents indicated that it is exceedingly difficult. Similarly, the majority $115(87.5 \%)$ of the respondents disagreed to the fact that it was the easiest subject to study at the Senior High School.

With respect to the students' perceptions about the relevance of the teaching and learning of the Geography subject, the majority $90(75.0 \%)$ of the respondents agreed that Geography helps them to understand the problems in the world like earthquakes, volcanoes, and many others. In addition, the majority $83(69.2 \%)$ of the respondents agreed that knowledge from Geography helps them to extend support to other nations. Furthermore, more than half $82(68.3 \%)$ of the respondents agreed that knowledge from Geography helps people to improve natural living conditions. Interestingly, most $68(56.7 \%)$ of the respondents agreed to the fact that Geography helps them to know what is happening in other parts of the world. Also, the majority $93(77.5 \%)$ of the respondents agreed that Geography helps them to know how to read maps. Again, a little more than half $61(50.8 \%)$ of the respondents agreed that Knowledge from Geography will help them to fit in any part of the world.

7.2 Research Question Two: What are the attitudes of Senior High School students toward the teaching and learning of Geography?

Items from section $\mathrm{C}$ of the questionnaire were analysed to address this research question. Table 4 presents the analyses of the descriptive mean and standard deviation values of the various items. 
Table 4: Distribution of Respondents by their attitudes toward Geography

\begin{tabular}{lcc}
\hline \multicolumn{1}{c}{ Statement } & Mean & SD \\
\hline 1. I put a lot of effort into assignments in Geography. & 4.29 & 1.082 \\
2. I find Geography work easy. & 4.28 & .970 \\
3. Time goes quickly when Geography lesson is in progress. & 4.27 & .868 \\
4. If I get stuck in the subject, I keep trying to figure it out. & 4.25 & .809 \\
5. I look forward to Geography extra-classes. & 4.15 & .974 \\
6. I work hard during Geography lessons. & 4.10 & 1.126 \\
7. I get good marks in Geography. & 4.07 & .987 \\
8. My marks are in the top half of the class. & 3.61 & 1.248 \\
9. I find it easy to concentrate when Geography lessons are in progress. & 1.58 & .977 \\
10. Doing Geography helps me to understand the world around me. & 3.93 & 1.109 \\
\hline Average Mean/Standard Deviation & $\mathbf{3 . 8 5}$ & $\mathbf{1 . 0 1 5}$ \\
\hline 1. I wish I did not have to do Geography. & 4.20 & .977 \\
2. My mind wanders off the subject when we are doing it. & 4.06 & .944 \\
3. I get low marks from my assignments in Geography which mostly affects & 3.93 & 1.109 \\
position in class. & 3.77 & 1.083 \\
4. I cannot see any use in the subject. & 3.63 & 1.281 \\
5. I feel relieved when Geography lessons are over. & 2.09 & 1.16 \\
6. My performance in Geography is below average. & 2.04 & 1.12 \\
7. I have no plans to seek further studies in Geography at the tertiary level. & 2.49 & 1.37 \\
8. Time goes slowly when Geography lesson is in progress. & 3.15 & 1.148 \\
9. I mostly give up when I get stuck while learning Geography. & 4.06 & .984 \\
10. Geography is a boring subject. & $\mathbf{3 . 3 4}$ & $\mathbf{1 . 1 1 7 6}$ \\
\hline Average Mean/Standard Deviation & & 3.96
\end{tabular}

From data on Table 4 and using the cut-off point of 2.5, we found out that students have positive attitude towards the teaching and learning of Geography. A check of both sets of attitudes (positive and negative) shows that they were all above the average cut-off point of 2.5, though the overage average score for the positive attitudes $(\mathrm{M}=3.85, \mathrm{SD}=1.015)$ is higher than the average mean of the negative attitudes $(\mathrm{M}=3.34, \mathrm{SD}=1.1176)$.

7.3 Research Question Three: What teaching and learning resources are available for the teaching and learning of Geography in the Senior High Schools?

To provide answer to this research question, the respondents were made to answer a 4-item questionnaire constructed on a four-point Likert scale ranging from "Strongly Disagree (1), Disagree (2) Agree (3) and Strongly Agree (4)". The responses were then categorized into two main divisions: "Agree"' and "Disagree". The analysis of their responses is presented in Table 5 .

Table 5: Distribution of Respondents by Teaching and Learning material available in their schools

\begin{tabular}{|c|c|c|c|c|}
\hline \multirow[t]{2}{*}{ Statement } & \multicolumn{2}{|c|}{ Agree } & \multicolumn{2}{|c|}{ Disagree } \\
\hline & Freq. & $\%$ & Freq. & $\%$ \\
\hline $\begin{array}{l}\text { 1. The teacher uses effective teaching aids such as cardboard, models, etc. for } \\
\text { illustrations. }\end{array}$ & 78 & 65.0 & 42 & 35.0 \\
\hline $\begin{array}{l}\text { 2. Reading materials such as textbooks, handouts, etc. are used by my } \\
\text { geography teacher in teaching Geography. }\end{array}$ & 120 & 100.0 & 0 & 0.0 \\
\hline $\begin{array}{l}\text { 3. Teachers and students occasionally develop charts, models, etc. for } \\
\text { Geography lessons. }\end{array}$ & 79 & 65.8 & 41 & 34.2 \\
\hline $\begin{array}{l}\text { 4. Visual materials (bulletin board, pictures, charts,) are used by my teacher } \\
\text { in teaching Geography. }\end{array}$ & 87 & 72.5 & 33 & 27.5 \\
\hline $\begin{array}{l}\text { 5. Audio-visual materials such as TV, computers, etc. are usually used by my } \\
\text { teacher. }\end{array}$ & 0 & 0.0 & 120 & 100.0 \\
\hline
\end{tabular}

The data on Table 5 shows the teaching and learning materials available in the Senior High Schools in the Cape Coast Metropolis as was indicated by the respondents.

All $120(100.0 \%)$ of the respondents generally agreed that reading materials such as textbooks, handouts etc. are used by their Geography teachers in teaching. Nevertheless, the same number $120(100.0 \%)$ of the respondents disagreed to the fact that audio-visual materials such as TV, computers, etc. are usually used by their teachers in teaching.

The majority $78(65.0 \%)$ of the respondents agreed that their teachers use effective teaching aids such as cardboard, models, etc. for illustrations. Furthermore, most $79(65.8 \%)$ of the respondents agreed that teachers and students occasionally develop charts, models, etc. for Geography lessons. Finally, the majority 87 (72.5\%) agreed 
that visual materials (bulletin board, pictures, charts,) are used by their teachers in teaching Geography.

\subsection{Discussion of Research Findings}

In this section, the findings are discussed in relation to:

1. How the Senior High School students perceive the teaching and learning of Geography.

2. The attitudes of Senior High School students toward the teaching and learning of Geography.

3. The teaching and learning resources available for the teaching and learning of Geography in the Senior High Schools.

\subsection{How the Senior High School students perceive the teaching and learning of Geography}

The findings on the Table 3 clearly shows some perceptions of the students in Senior High Schools in the Cape Coast Metropolis in the teaching and learning of Geography. The study revealed that the students used in the study perceive Geography as exceedingly difficult to learn and understand. This might be because the Geography subject involves a lot of drawings and terminologies, etcetera.

The study revealed further that the students perceived the Geography subject relevant as it helps them to understand the problems in the world like earthquakes, volcanoes, and many others. This is in agreement with Garnet's (1965) perception that the function of Geography is to train future citizens to imagine accurately the conditions of the great world stage so as to help them think sanely about the problems of the world around. This therefore implies that with the knowledge of Geography, students can easily understand natural phenomena and know how to control their occurrence in future. In addition, the subject helps them to extend support to other nations. The finding agrees with Gopsill (1966) comment that Geography, whether concerned with a district, a country or a world-wide phenomenon, will obviously demonstrate the need for widespread co-operation between all the people on the earth. He even continued that, Geography will, thus, instill in the young people the variable idea of solidarity, which should be exhibited among all men, of which the UNESCO calls international understanding. Indeed, students after studying Geography at school will be able to empathize with people from other parts of the world engaged in natural disasters and even offer them the necessary assistance.

Furthermore, they indicated that knowledge acquired from Geography helps people to improve natural living conditions. The present finding corroborates Gopsill's (1966) view that Geography will be attractive to the student to the extent that he perceives how it contributes to the improvement of his existing conditions which it describes and explains. Again, Geography helps them to know how to read maps. This finding is also in agreement with Hopwood's (2004) finding that students' perceptions of main geography skills were map skills, life skills, understanding perspectives of other people, and understanding geographic knowledge. Also, the students indicated that Geography helps them to know what is happening in other parts of the world which agrees with Amannor's (2004) study. The study explains that geography helps students know what is happening in other parts of the world apart from their place of residence or countries, the relationship between human activities and the environment is clearly identified in geographic study. Finally, they made it clear that knowledge from Geography will help them to fit in any part of the world. This finding supports Acheampong and Dickson's (2000) view that the geographer who has learned to reason logically and follow the scientific methods can work successfully in any job where administrative and general supervisory skills are required.

\subsection{The attitudes of Senior High School students toward the teaching and learning of Geography}

The findings clearly indicate that students have positive attitude towards the teaching and learning of Geography. The findings of the present study agree with several studies reviewed. Some of these include the findings of Boabeng and Obour (2010) who found that students have a positive attitude towards Geography as far as other general art subjects are concerned, which they even agreed with the students because they (students) have prior knowledge of the subject from the basic schools before entering the Senior High Schools. Other related studies found that students have a positive attitude toward the study of Geography includes the works of Havorson and Wescoat (2002); Spronken-Smith (2005) and Baker and White (2003), etcetera. The present study in comparison with the previous ones indicate that Geography is an interesting subject and hence teachers must motivate students in the course of teaching to develop positive attitude towards it as it not only going to benefit them to pass their examinations but also will help them to develop personally. According to Acquah (2017), motivation is the fuel that drives people towards achieving their goals and objectives

\subsection{The teaching and learning resources available for the teaching and learning of Geography in the Senior High Schools}

The findings of the study revealed that reading materials such as textbooks, handouts etc. are used by the Geography teachers in teaching. The students again indicated that their teachers use effective teaching aids such as cardboard, models, etc. for illustrations. Moreover, according to Kodua-Ntim (2020), Libraries have traditionally been a source of information and knowledge. Students made good use of the library to aid the learning 
of geography. Furthermore, most of the students made it noticeably clear that teachers and students occasionally develop charts, models, etc. during Geography lessons. Finally, most of the students said visual materials (bulletin board, pictures, charts,) are used by their teachers in teaching Geography. The present findings 'are in line with Tamakloe's (1991) study which supports the idea that instructional materials are effective mechanisms of helping students to build clear and accurate concepts, which he emphasized that teaching and learning materials can direct students' interest and promote their active participation in the teaching and learning process. This implies that teaching and learning resources help students to understand very well the concepts in Geography instead of teaching abstractly, therefore there is the need for Geography teachers to continuously employ them in their teaching.

Nevertheless, the findings indicate that audio-visual materials such as TV, computers, etc have never been used by the Geography teachers in the selected schools. Though, Tamakloe et al., (1996) recommended that audiovisual resources are capable of widening students' horizon and range of experiences. This implies that as students learn through audios and videos like the use to television programmes and computer they may easily understand instead of always sticking to the tradition teaching methods.

\subsection{Conclusions}

Based on the results of the study, conclusions can be drawn from the whole research work. The findings of this research were based on the research questions. From the study one major problem investigated at the Senior High School was the students' perceptions about the teaching and learning of the Geography subject. The larger number of students perceive the study of Geography as very relevant as it contributes to the development of people and nations and their ability to control certain natural disasters, know what is happening in other parts of the world and therefore extend their support to them. Although, the students were afraid the content of Geography is very technical, as it involves drawings, calculations and critical thinking which makes it exceedingly difficult to pass. Hopwood (2004) is of the view that geography as a subject about the world, people and ways of life, countries, world problems, and a dynamic subject in which multiple perspectives are considered. Students' perceptions of main geography skills were map skills, life skills, understanding perspectives of other people, and understanding geographic knowledge. From the findings, the researchers can conclude that geography helps in national development of people and the ability to control national disasters.

Moreover, with respect to the students' attitude towards the teaching and learning of Geography in their schools, majority of them responded positively. For instance, most of them made it very clear that they put a lot of effort into answering assignments given them, as they learn the subject very well, it makes them answer questions with ease and therefore come out with good grades, and their affection for the subject makes them feel time runs very quickly when Geography lessons are in progress as they would wish to enjoy it all day. This is supported by Walker (2006), students have higher achievement with subject matter when they are in a good mood, enjoy what they are doing, and have a positive attitude. He further stated that when students come together as groups, they have affection for the course which helps them in obtaining good grades. From the findings and what the literature is saying the researchers conclude that students put a lot of efforts in answering assignments that helps them in having good grades and again they also perceive that when they are in good mood and have affection for the course, they excel in the subject.

Finally, the majority of the teachers in the various Senior High Schools are more familiar with the tradition teaching and learning resources than the modern ones like the use of audio-visual aids. For instance, the students indicated that their teachers prefer the use of certain teaching and learning materials like cardboards, models, pictures, charts and bulletin boards to other modern ones which would easily facilitate the students' comprehension of the subject like television, computers and other electronic devices. This is supported by Tamakloe (1996) who supports the idea that instructional materials are effective mechanisms of helping students to build clear and accurate concepts. He further stated that the traditional teaching method in various institutions facilitated a better understanding of the study. In addition, materials can direct students' interest and promote their active participation in the teaching and learning process. From the findings and what the literature is saying, the researchers can conclude that teaching and learning materials like cardboards, models and charts contribute to the effective learning of the students.

\subsection{Recommendations}

Based on the research findings, the following recommendations are made.

1. Since the findings of the study has revealed that knowledge in Geography plays a key role in our lives and help us to adapt to our environment, teachers in the various schools should motivate their students to take Geography lessons very seriously and learn it well as it could be of relevance to them and their nation in the near future.

2. The teachers, educational stakeholders and other related institutions should equip students to be able to solve challenges they may encounter in dealing with issues related to the attitudes of students towards the teaching 
and learning of Geography.

3. Government and other stakeholders should provide schools with modern teaching and learning resources so as to help teachers to explain very well Geography concepts to the understanding of their students.

\section{REFERENCES}

Acheampong, C., \& Dickson, P. (2000). Geology and hydrogeology of the snake valley area. Western Utah and Eastern Nevada. Elvis Inc

Acquah, A. (2017). Implications of the Achievement Motivation Theory for School Management in Ghana: A Literature Review. Research on Humanities and Social Science, 7, 10-15.

Amannor, K. (2004). Essence studying geography in modern world. Accra: Best Inc.

Baker, T., \& White, S. (2003). The effects of G.I.S. on students' attitudes, self-efficacy, and achievement in middle school science classrooms. Journal of Geography, 102(6), 243-254.

Dickson, G. E., \& Wiersma, W. (1980). Research and evaluation in teacher education: A concern for competent, effective teachers. Ohio: University of Toledo.

Dickson, P., \& Acheampong, C. (1991). Research and evaluation on the importance of geography. Accra: Alex Press.

Fletcher, A. (2005). Meaningful student involvement guide to students as partners in school change. Olympia, WA: Sound Out.

Garnett, A. C. (1965). Body and mind: The identity thesis. Australasian Journal of Philosophy, 43(1), 77-81.

Ghana Education Service, (2010). The geography syllabus for senior high schools, Accra, CRDD.

Hopwood, N. (2004). Pupils' conceptions of geography: Towards an improved understanding. International Research in Geographical and Environmental Education, 13 (4), 348-361.

Jones, L. (2007). The student-centered classroom. United Kingdom: Cambridge University Press.

Kartz, D. (1960). The function approach to the study of attitude. Public opinion. Quarterly, 24 (2), 163-170.

Kodua-Ntim, K. (2020). Usage of open access institutional repositories in University libraries in Ghana (Doctoral dissertation).

Moore, M. (1989). Three types of interaction. American Journal of Distance Education, 13(3-4), 147-148.

National Research Council (2006). Learning to think spatially. Washington, D.C.: The National Academies Press.

Rubenstein, N. (2003). The concept of geography. London: Kinky Press.

Sir Mackinder (1887). The nature of geography. Michigan: John Evans \& Sons, Inc.

Spronken-Smith, R. (2005). Implementing a problem-based learning approach for teaching research methods in geography. Journal of Geography in Higher Education, 29(2), 203-221.

Tamakloe, E. K. (1991). The nature of geography studies and its curriculum implications. Journal of Institute of Education, 2(1), 4-7.

Tamakloe, E. K., Atta, E.T., \& Amedahe, F.K. (1996). Principles and methods of teaching. Accra: Black Mask Ltd.

Terry, W.S. (2006). Learning and memory: Basic principles, processes, and procedure. Boston: Pearson Education, Inc.

Walker, S. (2006). Development and validation of the test of geography-related attitudes. Journal of Geography, 105(4), 175-181. 